\title{
Investigation of anodic behaviour of phenylethers in non-aqueous solvents on platinum and glassy carbon electrodes
}

\author{
László Kiss $^{1,2} \cdot$ Ferenc Kovács ${ }^{1}$ Sándor Kunsági-Máté ${ }^{3}$
}

Received: 21 April 2020 / Accepted: 29 November 2020 / Published online: 23 December 2020

(c) The Author(s) 2020

\begin{abstract}
Electrooxidation of selected phenylethers was investigated (2-phenoxyethanol, anisole, $o$-nitrophenyl octyl ether, diphenylether, fenoxycarb) on platinum and glassy carbon electrodes. The chosen solvents were acetonitrile, dimethyl sulphoxide, 1-propanol and mesityl oxide. In acetonitrile, at around $2 \mathrm{~V}$ characteristic voltammetric peaks appeared for all compounds. In dimethyl sulphoxide and 1-propanol, no relevant peak appeared due to the high overlapping with solvent electrooxidation. During anodic oxidation of $o$-nitrophenyl octyl ether and fenoxycarb, a bimolecular reaction takes place predominantly. In mesityl oxide due to its unsaturated bond, identical behaviour was observed for majority of compounds and the differences between the two electrodes are also highlighted in the surface studies. The images made with the aid of an optical microscope showed the formation of islands of products for each substrate after deposition from mesityl oxide.
\end{abstract}

Keywords Phenylether $\cdot$ Electrodeposition $\cdot$ Non-aqueous $\cdot$ Fouling $\cdot$ Voltammetry

\section{Introduction}

Many organic compounds serve as monomer in the formation of coatings whose conductivities vary in a very large scale. It is known that phenolic compounds usually deactivate the commonly used electrodes during anodic oxidation, but there are few works about the electrochemistry of phenylethers in non-aqueous solvents. Those studies are restricted to preparative electrolyses, reaction kinetics in different solvents [1-10]. The examination of building up organic layers on electrode surfaces as modifiers offers useful information for several applications. The different monomers react on different electrodes in an identical process depending on the solvent used for electrodeposition. The porosity varies by ensuring the appropriate conditions for experiment.

There are some works which aim at determination of phenylether compounds in non-aqueous low permittivity

László Kiss

kissl@gamma.ttk.pte.hu

1 Department of General and Physical Chemistry, University of Pécs, Ifjúság street 6, Pécs 7624, Hungary

2 János Szentágothai Research Center, Ifjúság útja 20, Pécs 7624, Hungary

3 Department of Organic and Pharmacological Chemistry, University of Pécs, Honvéd street 1, Pécs 7624, Hungary environments with ultramicroelectrodes. As antioxidant, several compounds are applied in biodiesel samples and some of them belong to phenylethers like tert-butylhydroxyanisole. This is electroactive and efforts were made for its electroanalytical determination mixed with ethanol in biodiesel samples $[11,12]$. This anisole derivative plays similar role also in vegetable oils and direct determination in acetonitrile and benzene/ethanol/ $\mathrm{H}_{2} \mathrm{SO}_{4}$ is possible [13]. 2-phenoxyethanol is widely used as intermediate in numerous organic synthesis. On the other hand, 2-phenoxyethanol is present in cosmetics so efforts were made for its determination in non-aqueous environments $[14,15]$.

The accessible potential window highly influences the usefulness of a solvent, and, on the other hand, the solvation of substrate molecules, inertness and permittivity determine their behaviour significantly. Acetonitrile supports these basic requirements so its use in electrochemical studies became very frequent. Therefore, this was one of the selected solvents here to study all of the mentioned compounds.

In a previous study, phenol was investigated in mesityl oxide solvent and identical oxidation behaviour could be observed on platinum electrode [16]. As mesityl oxide has an unsaturated carbon-carbon double bond, this solvent participates in the polymerization processes initiated by the electrochemically generated radicals which were 
demonstrated in that work. Considering that the electrode material has significant effect on the electropolymerization of phenol, in this work the studies of phenylethers were extended to platinum and glassy carbon electrodes. On the other hand, the solvent itself may produce surprising results so mesityl oxide was chosen also as solvent.

\section{Experimental}

All solvents and solutes were analytical grade, and the electrodes were the following: platinum rod counter, silver wire reference and disc-shaped working electrodes with $1 \mathrm{~mm}$ in diameter (platinum, glassy carbon, which were the products of eDAQ). Before each experiment, the working electrodes were polished with aqueous suspension of alumina powder on a polishing cloth. Finally, they were thoroughly washed with deionized water and ultrasonicated for some minutes to remove the residual of alumina particles. After removal of water droplets with tissue paper from their surfaces, they were thoroughly dried by embedding the electrode bodies in dry acetone to remove the traces of water. In all experiments, a lipophilic salt tetrabutylammonium perchlorate (TBAP) was used as supporting electrolyte. The three-electrode cell was connected to a potentiostat (Dropsens, Spain).

An optical microscope was used for making images about some selected surfaces, and the electrode was fixed with the electrodeposited layers under its ocular. Before electrode fixing, the organic layer was washed thoroughly with the pure solvent to remove the unreacted monomers and supporting electrolyte and dried.

\section{Results and discussion}

\section{Studies of the selected phenylethers}

\section{2-phenoxyethanol}

One of the aromatics having substituent-free benzene moiety is 2-phenoxyethanol so it was investigated in higher concentration than the previously published works $(20 \mathrm{mM})$. When this compound is present in low concentration in these conditions, the anodically generated radical can react with the traces of water producing quinonic dimers and ethylene glycol [15]. Here, the anodic oxidation of 2-phenoxyethanol was studied firstly in acetonitrile solvent between 0 and $2.3 \mathrm{~V}$. At around $2 \mathrm{~V}$, a steep voltammetric peak appeared with both platinum and glassy carbon electrode. In the two further scans, the peak heights were very small indicating the rapid deactivation.

Concerning the mechanism of 2-phenoxyethanol electrooxidation due to the observation of deactivation a bimolecular process can be established in aprotic environment (Scheme 1). This follows the charge transfer process of monomer leading to the formation of organic deposit in further coupling processes. On the surface of platinum, there is no functional group capable of reacting with radicals. The surface of glassy carbon is usually covered by a large number of phenolic hydroxy groups as potential sites for grafting. The similarity of the voltammograms measured with the two electrodes suggests that predominantly bimolecular reactions take place at both electrodes where new monomers can join by nucleophilic attack due to the hydroxy group in the aliphatic part to the electrochemically generated radicals promoting the polymerization. In an earlier work where 2-phenoxyethanol anodic oxidation was investigated in $20 \mathrm{mM}$ concentration in aqueous solution weak deactivation occurred as water solvent acted predominantly as nucleophilic agent suppressing the polymerization. In parallel with this process, the phenolic hydroxy groups on surface of glassy carbon act as potential candidates for the formed radicals as they have also nucleophilic nature and it resulted in deposit formation.

The voltammograms recorded in dimethyl sulphoxide and 1-propanol (Fig. 1b and c) contain only few useful information. Earlier works showed that these solvents begin to oxidize at lower potentials and the overlapping with substrate electrooxidation is very significant [17]. However, the curves are nearly identical, particularly in dimethyl sulphoxide it indicates that the formed polymers can dissolve in the bulk or few oligomers can bind weakly onto the electrode surface. Due to this observation, the use of these solvents was neglected in the further investigations. It is unusual that in dimethyl sulphoxide and in 1-propanol no relevant oxidation peak of substrate showed up, but solvent permittivity would elevate it similarly to acetonitrile. However, overlapping of solvent electrooxidation has high contribution to the curves other phenomena can also be in play like diffusion hindrance towards substrate molecules caused by weakly adsorbed products.

An interesting solvent is mesityl oxide as it was shown in one of our recent works [16]. Anodic peaks at higher potentials than $2 \mathrm{~V}$ are due to electrooxidation of substrate, but in the reverse scan, a small reduction peak appeared at around $0.5 \mathrm{~V}$. The latter could be only observed in mesityl oxide and with platinum electrode attributed to the oxo groups of adsorbed organic layer. The shape of voltammograms depended highly on the timescale in case of phenol on platinum electrode. When they were taken immediately after each other (without pauses) after passing a minimum the peak currents of subsequent scans reached a steady state. Contrarily, the insertion of pauses resulted in continuous deactivation. Here, when the substrate was 2-phenoxyethanol dissolved in mesityl oxide showed very similar behaviour to phenol published in [16] when ten voltammograms 
Scheme 1 Mechanism of 2-phenoxyethanol electrooxidation in acetonitrile
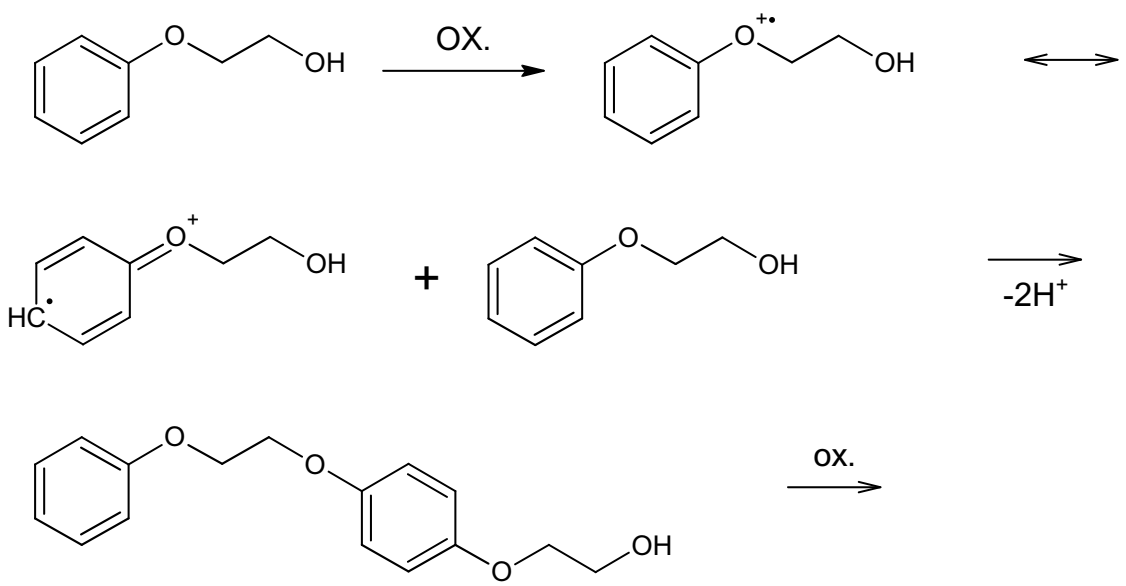<smiles>OCCOc1ccc(OCC[O+]=C2C=C[CH]C=C2)cc1</smiles><smiles>[R4][C@H](C)CCCCCOc1ccc(OCCOc2ccc(OCCOc3ccccc3)cc2)cc1</smiles>

were repeated immediately after each other as the second scan had the minimum and the further values converged to a steady state (Fig. 1d). The remarkable difference between the two substrates (phenol and 2-phenoxyethanol) could be observed by inserting 10 min duration pauses between the recordings of the scans as the results were identical to the previous case where no pauses were inserted between the scans. This shows the significance of the 2-hydroxyethyl substituent contributing to the formation of a deposit with higher porosity and the latter quantity in reality did not change in time.

When glassy carbon was the working electrode in mesityl oxide, this substituent effect played also a significant role in the deactivation (Fig. 1e). Earlier [16], when phenol was the substrate the electrode fouled almost completely in the third scan suggesting the deposition of a compact layer. By the electropolymerization of phenol, we also concluded that the solvent mesityl oxide also takes part in the coating formation contributing to the low porosity. This situation occurs also in case of 2-phenoxyethanol where radicals form in the first step of electrode reaction combined with monomers of mesityl oxide resulting in copolymer. The three voltammograms recorded with 2-phenoxyethanol on glassy carbon show a reduced speed of deactivation compared with phenol. This can be attributed to substituent effect leading to increased porosity as in case of phenol the currents in the second step dropped to very low values after the large peak of the first scan.

As mesityl oxide is a poorly investigated solvent in electropolymerization processes, the deposits of selected monomers were studied also with optical microscope. For 2-phenoxyethanol, Fig. 2 shows the obtained images. They clearly show the remarkable differences between platinum and glassy carbon. However, particles of the product polymers are present on the surfaces but scratches as traces of incompleteness of polishing can be clearly seen only on platinum. This is in accordance with our recent results with phenol in mesityl oxide where a compact deposit formed covering the surface inhomogeneities. This difference appeared also by the other substrates (see later).

\section{Anisole}

The organic liquid anisole is also widely used in organic syntheses as it acts as precursor for preparation of many important substances like medicines, feromones and parfumes. This highly apolar solvent could not gain significant interest in electrochemistry due to its low permittivity $\left(\varepsilon_{\mathrm{r}}=4.30\right.$ [18]), and a very little work is found regarding its application as solvent for electrochemical investigations [19]. In that work, anisole proved an appropriate solvent for 

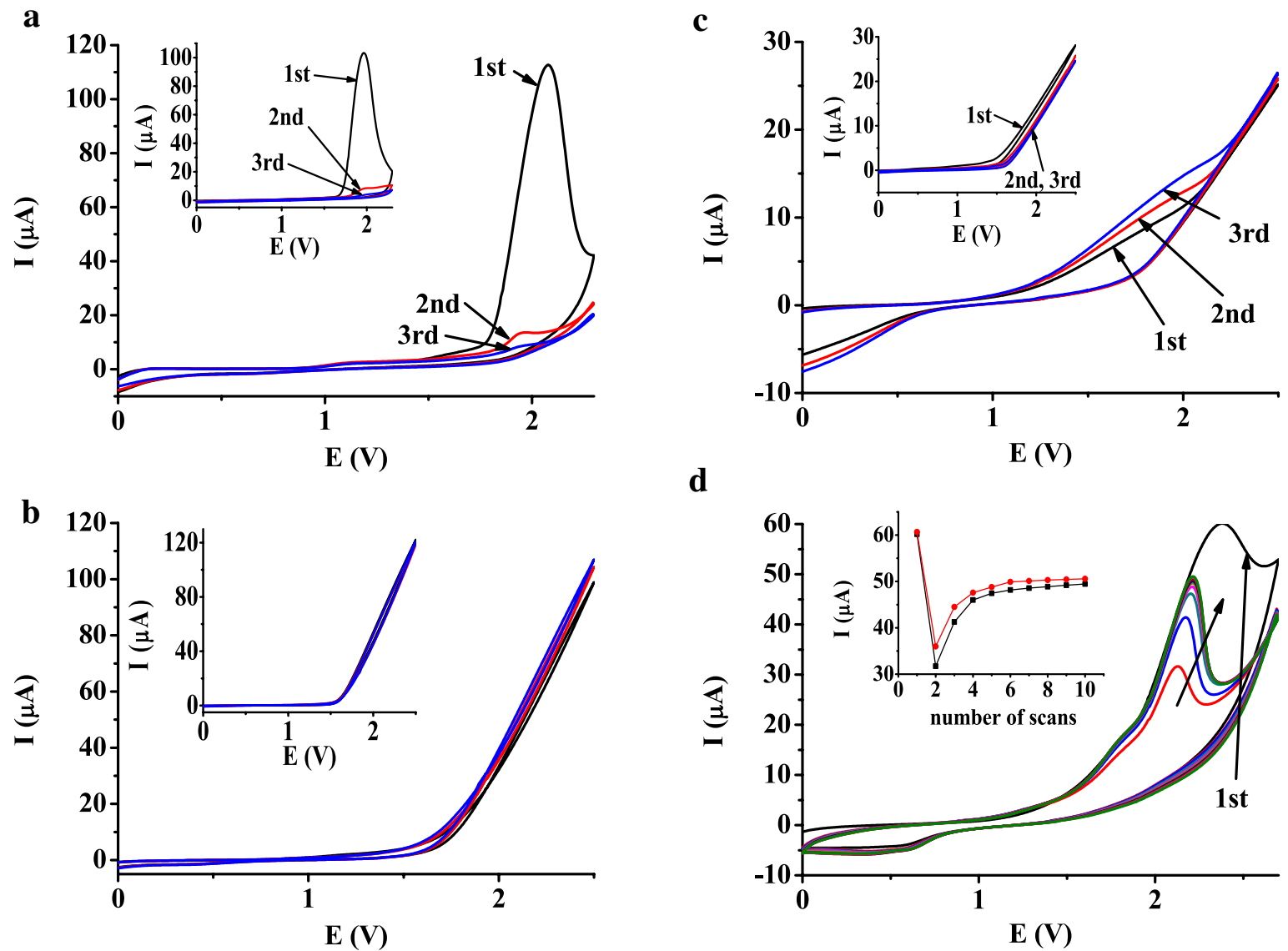

d
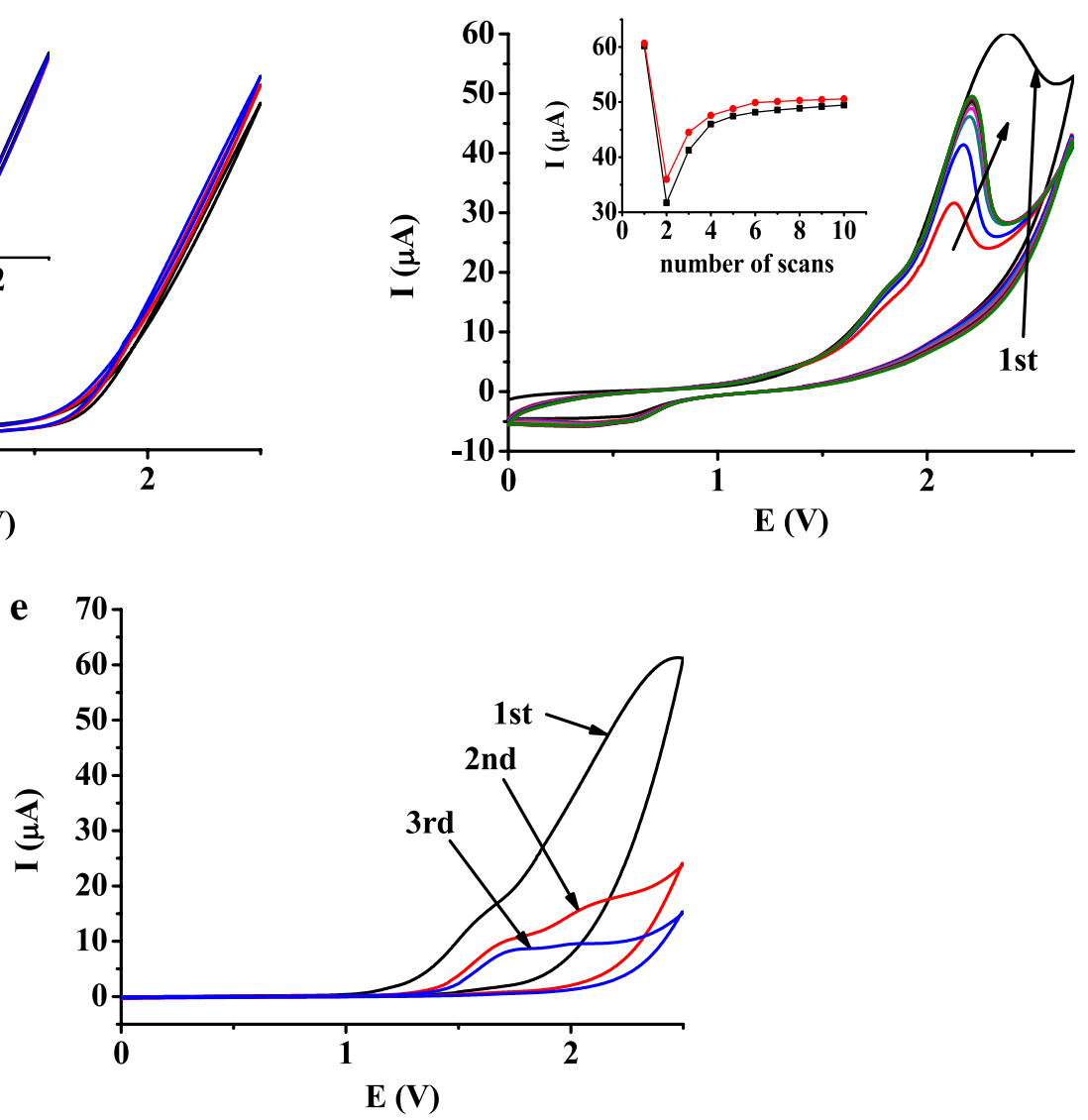

Fig. 1 Voltammograms of 2-phenoxyethanol on platinum electrode in acetonitrile (a), in dimethyl sulphoxide (b), in 1-propanol (c) and in mesityl oxide (d). Part (e) shows recorded curves with glassy carbon in mesityl oxide. Inset graph in part (a) displays the voltammograms

voltammetric study of $\pi$-electron systems like ferrocene. As cosolvent, anisole showed its favourable properties in alumina electrodeposition from melts of $\mathrm{AlCl}_{3}$ [20]. The electrochemical studies of thianthrene in liquid sulphur dioxide highlighted that the presence of anisole highly influences the products formed in an electrochemical step following the primary electrooxidation step [21]. taken with glassy carbon electrode in acetonitrile and in part (d) the peak currents obtained with platinum electrode in mesityl oxide. Analyte concentration $20 \mathrm{mM}, v=0.1 \mathrm{~V} / \mathrm{s}$, supporting electrolyte $0.05 \mathrm{M}$ TBAP

Anisole has a phenoxyl moiety similarly to 2-phenoxyethanol; therefore, similar behaviour might be established also in case when it is the substrate. Voltammograms of anisole in acetonitrile (Fig. 3a) taken between 0 and $2.3 \mathrm{~V}$ show an anodic peak at around $2 \mathrm{~V}$ where a radical forms promoting the rapid film formation on both platinum and glassy carbon electrode according to the following reaction (Scheme 2): 

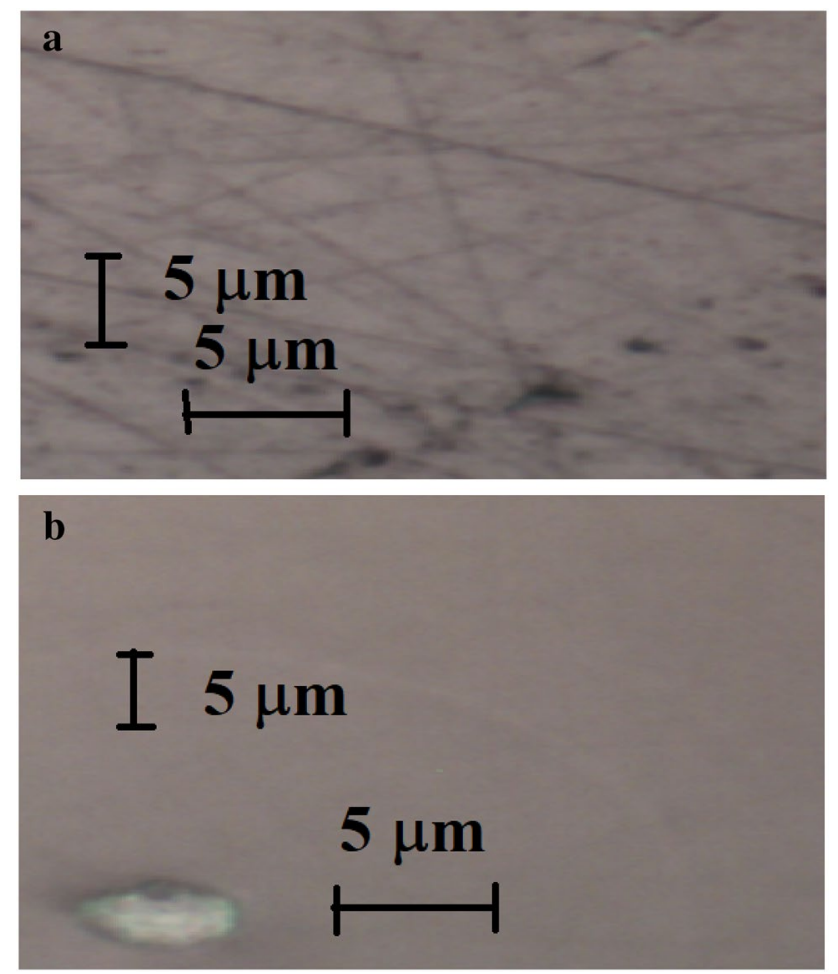

Fig. 2 Optical images of electrodeposited 2-phenoxyethanol from mesityl oxide on platinum (a) and on glassy carbon electrode (b)

The substrate firstly oxidizes on its oxygen atom resulting a radical cation which then transforms into a neutral radical by losing a proton. As the methoxy group is a highly electron donating group it helps the formation of radical in both the para and the two ortho positions of the benzene ring. Therefore, the other formed radicals can couple in all these positions. Studies showed that during electrooxidation of alkoxybenzenes the alkoxy groups are retained [22, 23]. The substitution of hydrogen in the $-\mathrm{OH}$ group with a methyl group resulted in a significant difference compared with phenol as the deactivation was smaller on both electrodes. This reaction takes place on the electrode surfaces as in work of Besbes-Hentati et al. [9] formation of trimers was verified and by $20 \mathrm{mM}$ concentration the process leads to polymerization. There is also visible difference compared with 2-phenoxyethanol as in its situation the deactivation was faster due to the nucleophilic attack of aliphatic hydroxy groups (see in an earlier part).

In mesityl oxide, a saturation behaviour took place for anisole on platinum electrode (Fig. 3b) by repeating ten scans immediately after each other. This is different from the results obtained with phenol and 2-phenoxyethanol, indicating that the substrate readily adsorbs on the previously formed deposit. This process did not show dependence on $\mathbf{a}$

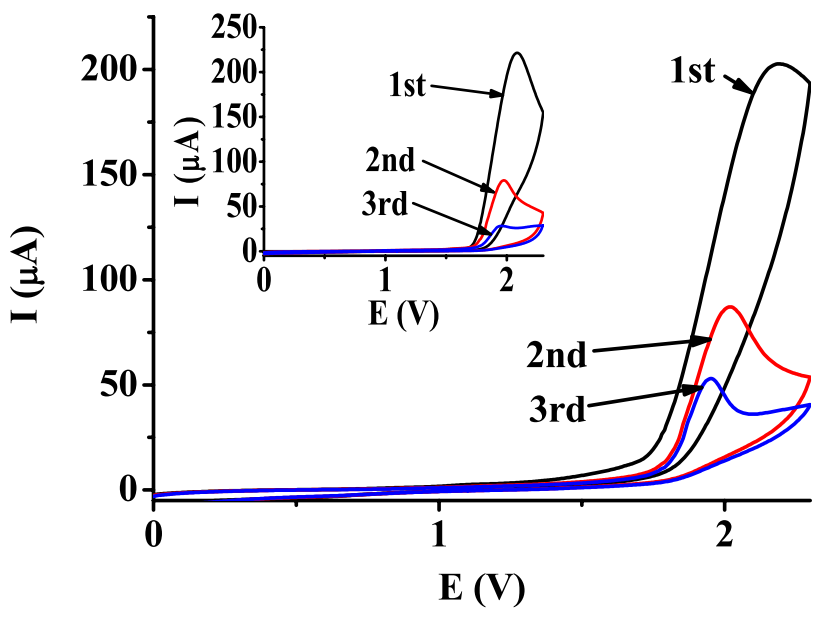

b
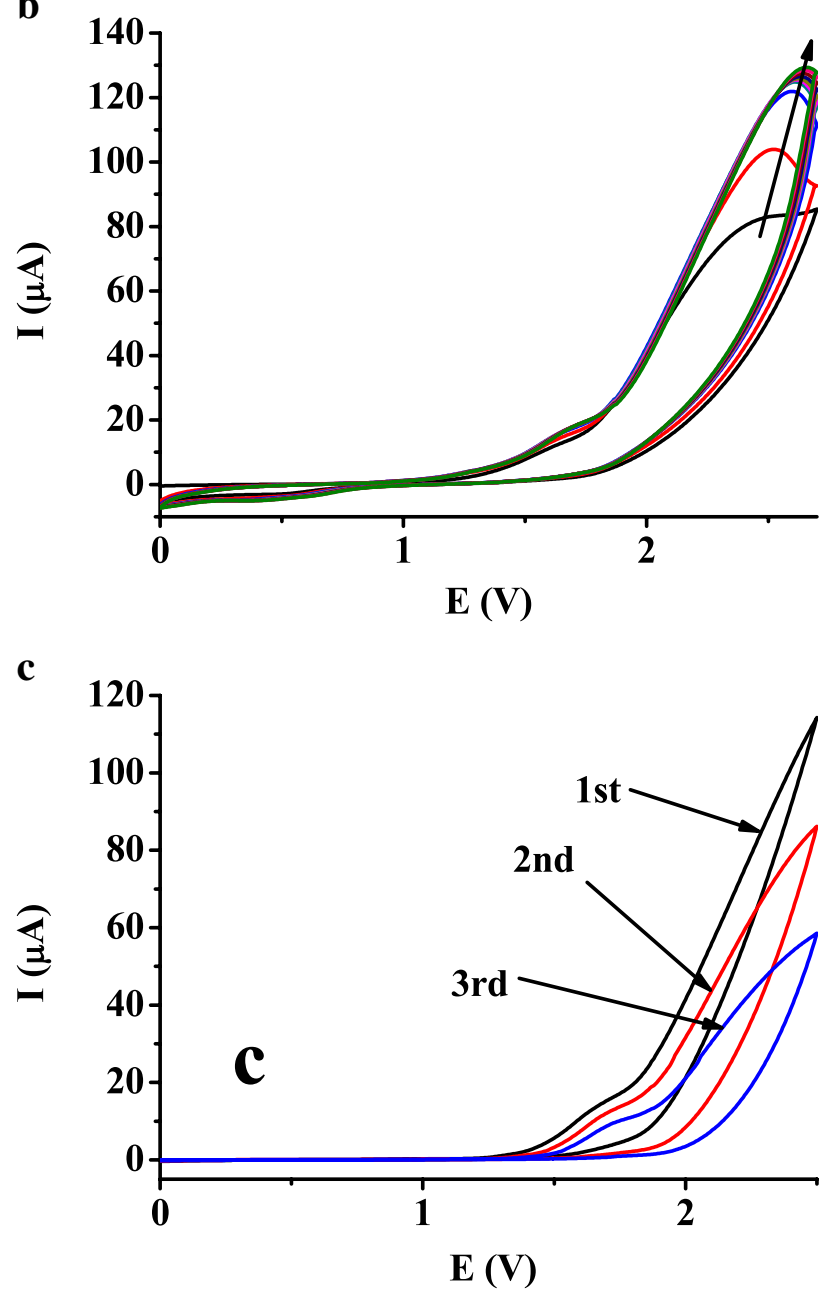

Fig. 3 Voltammograms for anisole electrooxidation in acetonitrile (a), in mesityl oxide on platinum (b) and in mesityl oxide on glassy carbon (c) electrode ( $c=20 \mathrm{mM}, v=0.1 \mathrm{~V} / \mathrm{s}$, supporting electrolyte $0.05 \mathrm{M}$ TBAP). Inset graph in part (a) displays results with glassy carbon electrode in acetonitrile 
2<smiles>COc1ccccc1</smiles><smiles>CCc1ccccc1</smiles>

$\mathrm{R}_{1}$

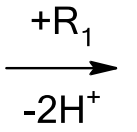

polymer

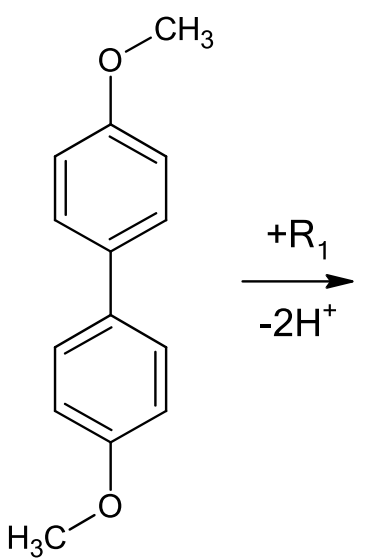

Scheme 2 Mechanism of anisole electrooxidation in the selected solvents

the timescale of measurement as it was demonstrated with different length of pauses. Glassy carbon electrode fouled remarkably but not with very rapidly as expected according to the previous findings involving participation of solvent in the polymerization process (Fig. 3c). The visible differences between platinum and glassy carbon are highlighted also here similarly to the case of 2-phenoxyethanol (Fig. 4).

\section{o-nitrophenyl octylether}

The chemical $o$-nitrophenyl octylether has a wide application as plasticizer, in chemical laboratories by preparation of ion-selective membranes. Only a few reports can be found in the literature about electrooxidation of nitrophenyl ethers, for example, redox behaviour of nitro diphenyl ethers [24]. According to the voltammograms in Fig. 5 recorded in acetonitrile, a bimolecular reaction takes place predominantly where coupling of two electrochemically generated radicals results in a dimer. Namely, on platinum there was not any decline in the peak currents only a little on glassy carbon (Fig. 5a). An additional experiment where scan rate was changed in the $20-120 \mathrm{mV} / \mathrm{s}$ interval demonstrated the adsorption controlled behaviour on platinum as the peak current-scan rate function gave linear behaviour. As $o$-nitrophenyl octylether is a surfactant, the substance adsorbs readily on solid surfaces. Due to sterical hindrances and the deactivating nitro group, further anodic oxidation of the dimer
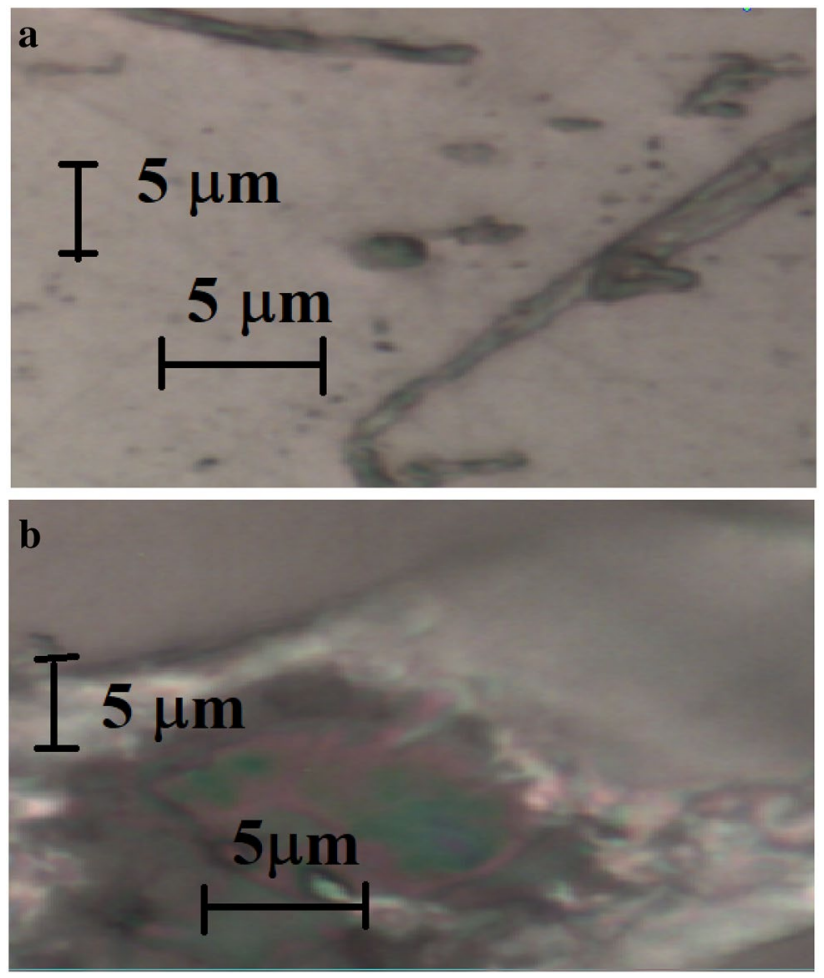

Fig. 4 Optical images of electrodeposited anisole from mesityl oxide on platinum (a) and on glassy carbon electrode (b) 
$\mathbf{a}$

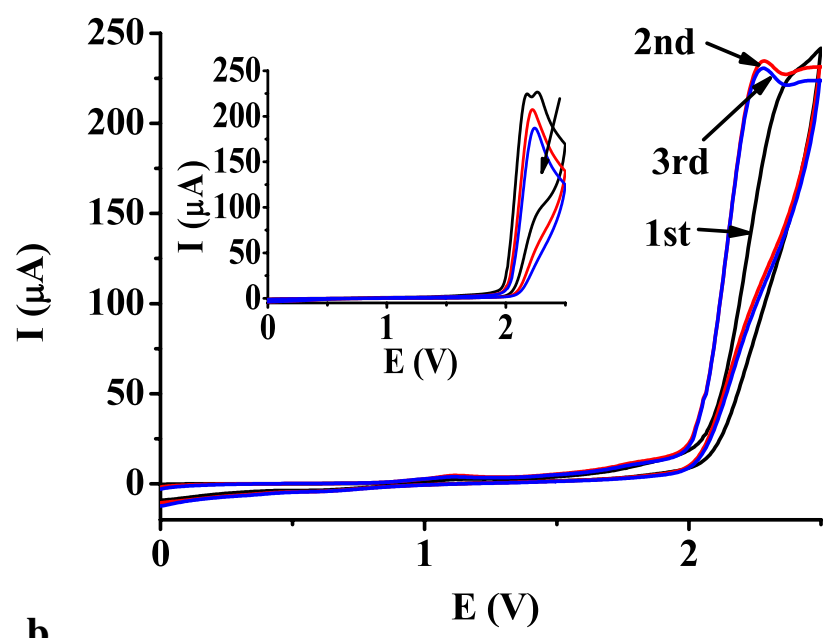

b

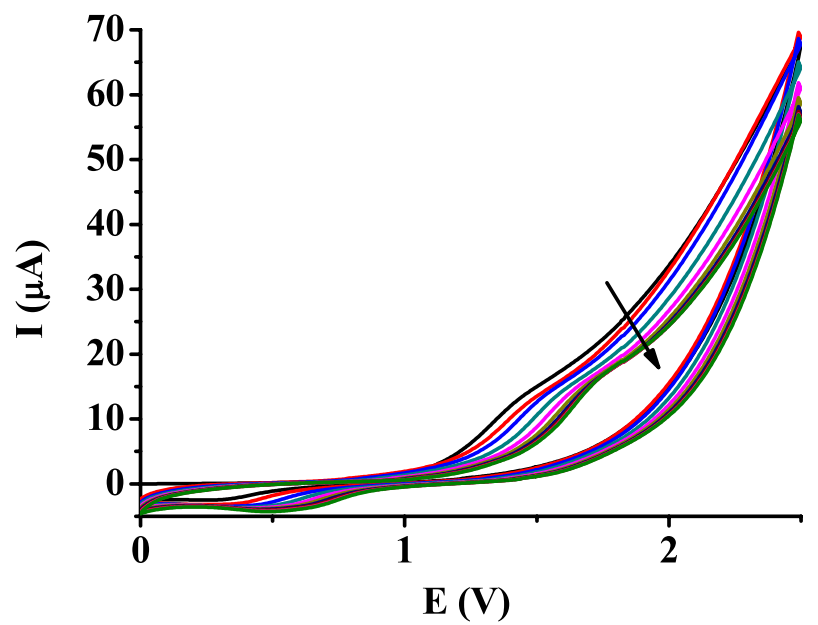

c

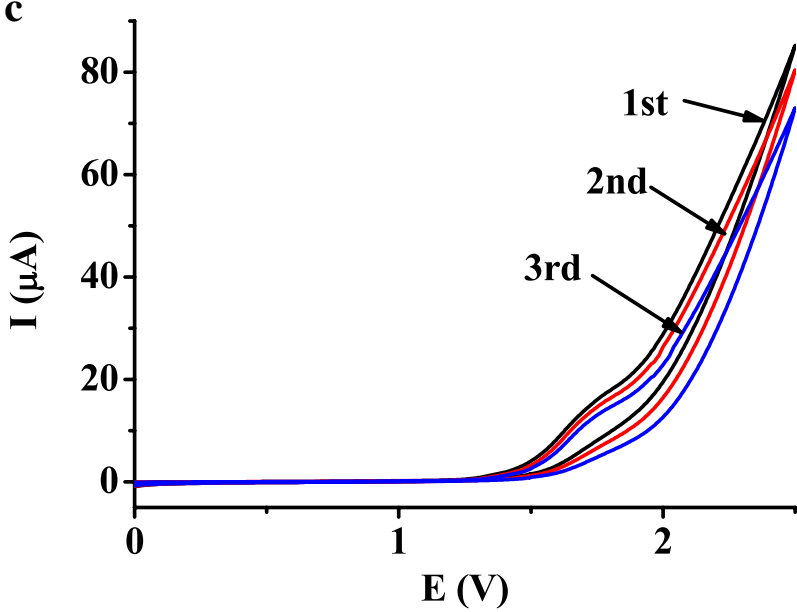

Fig. 5 Voltammograms of $o$-nitrophenyl octylether electrooxidation in acetonitrile (a) and in mesityl oxide on platinum (b) and in mesityl oxide on glassy carbon (c) electrode $(c=20 \mathrm{mM}, v=0.1 \mathrm{~V} / \mathrm{s}$, supporting electrolyte $0.05 \mathrm{M}$ TBAP). Inset graph in part (a) displays results with glassy carbon electrode in acetonitrile cannot occur as when the further oligomerization reaction would be significant the electrode would deactivate.

Similarly to the other phenylether compounds, as it was suggested by the voltammetric studies electrochemically generated polymerization takes place in acetonitrile at both electrodes (Scheme 3). Therefore, the further reaction of dimer to trimer and other oligomers can be neglected detailed also in the reaction scheme.

The results obtained by using mesityl oxide as solvent show nothing interesting features (Fig. 5b and c) as the curves were very similar and the surfactant characteristics of $o$-nitrophenyl octylether are mainly highlighted on scans recorded with glassy carbon electrode. The solvent has a high contribution to the current enhancement seen in the figure. In our recent work where the subsequent scans with glassy carbon electrode showed approximately $40 \%$ current decline in pure mesityl oxide and the weak deactivation in presence of $o$-nitrophenyl octylether clearly indicates that the solvent is excluded from the electrode/solution interface. Due to these results, nothing was found on the surfaces of electrodes with optical microscope (not shown).

\section{Diphenylether}

The apolar liquid being scarcely soluble in water has been attracted a wide application in analytical electrochemistry for facilitating adsorptive stripping analysis of organic substrates mainly in modified carbon paste electrodes [25, 26]. As electroactive material diphenylether was studied in the work of $\mathrm{Xu}$ et al. who prepared a conducting polymer in anhydrous acetonitrile containing sulphuric acid and boron trifluoride diethyl etherate [27] and the monomers joined through the phenyl groups in the para position.

Figure 6a shows the voltammetric curves scanned between 0 and $2.5 \mathrm{~V}$ on both electrodes in acetonitrile, and they fouled on the same way indicating the formation of an insulating polymer. This is in accordance with the results of $\mathrm{Xu}$ et al. as they obtained also low conductivity polymer without doping.

The measurements in mesityl oxide followed the same tendency with both electrodes, and on platinum, there was no significant dependence on the timescale (curves taken immediately after each other displayed in Fig. 6b). The tendency of current values suggested on the other hand some monomer adsorption as the currents increased a little also to a steady-state value. It was further verified when ten minutes equilibration times were inserted between the scans as the currents were a little higher in this case. Figure 7 displays the optical images where the islands formed from product can be found on the electrode surfaces. 
<smiles>[R]Oc1ccccc1[N+](=O)[O-]</smiles><smiles>[R]Oc1ccccc1[N+](=O)[O-]</smiles><smiles>[R]Oc1ccc(-c2ccc(O[R])c([N+](=O)[O-])c2)cc1[N+](=O)[O-]</smiles><smiles>[R]Oc1ccc(-c2cc(-c3ccc(O[R])c([N+](=O)[O-])c3)c(O[R])c([N+](=O)[O-])c2)cc1[N+](=O)[O-]</smiles><smiles>[R]Oc1ccc(-c2cc(-c3cc(-c4ccc(O[R])c([N+](=O)[O-])c4)c(O[R])c([N+](=O)[O-])c3)cc([N+](=O)[O-])c2O[R])cc1[N+](=O)[O-]</smiles>

Scheme 3 Mechanism of $o$-nitrophenyl octylether electrooxidation in the majority of solvents $\left(\mathrm{R}^{2}\right.$ is the octyl group and $\mathrm{R}_{3}$ denotes the radical formed in the first step of electrooxidation)<smiles>CCOC(=O)NCCOc1ccc(Oc2ccccc2)cc1</smiles>

Scheme 4 Dimerization reaction of fenoxycarb in the selected solvents 

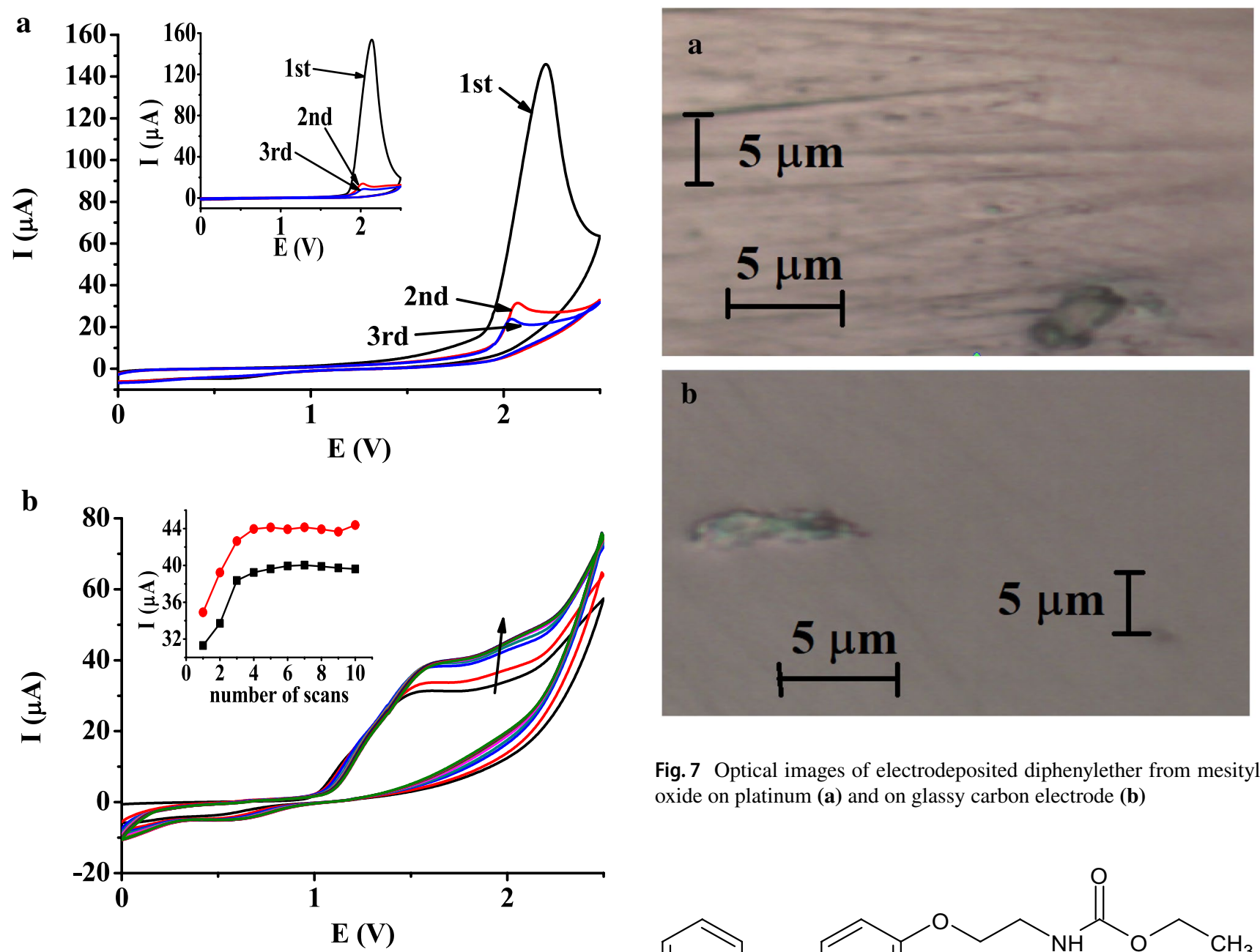

c

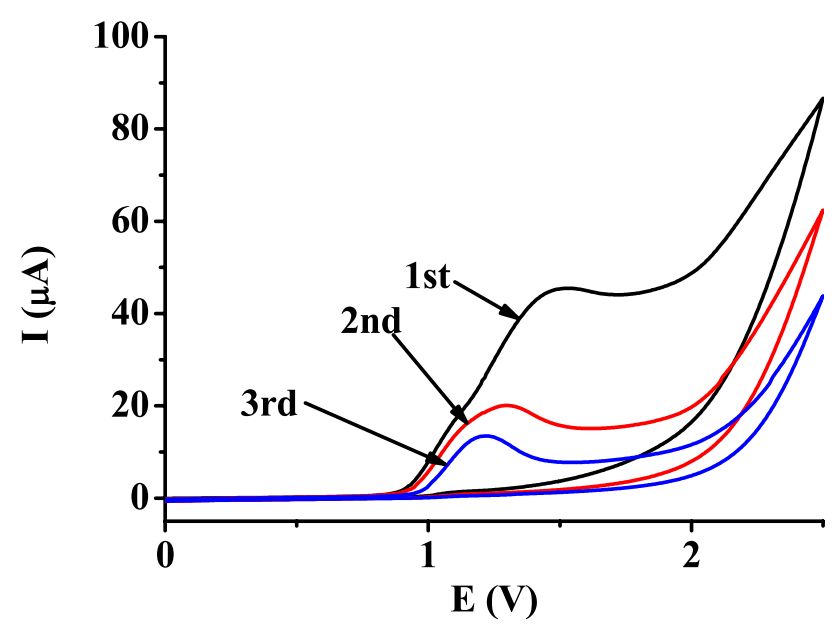

Fig. 6 Voltammograms for diphenylether electrooxidation in acetonitrile (a) and in mesityl oxide (b) on platinum electrode and graph (c) displays results with glassy carbon electrode in mesityl oxide $(c=20 \mathrm{mM}, v=0.1 \mathrm{~V} / \mathrm{s}$, supporting electrolyte $0.05 \mathrm{M}$ TBAP). Inset graph in (b) shows the peak current values for subsequent voltammograms taken immediately after each other (black dots) and by inserting $10 \mathrm{~min}$ for equilibration (red dots)

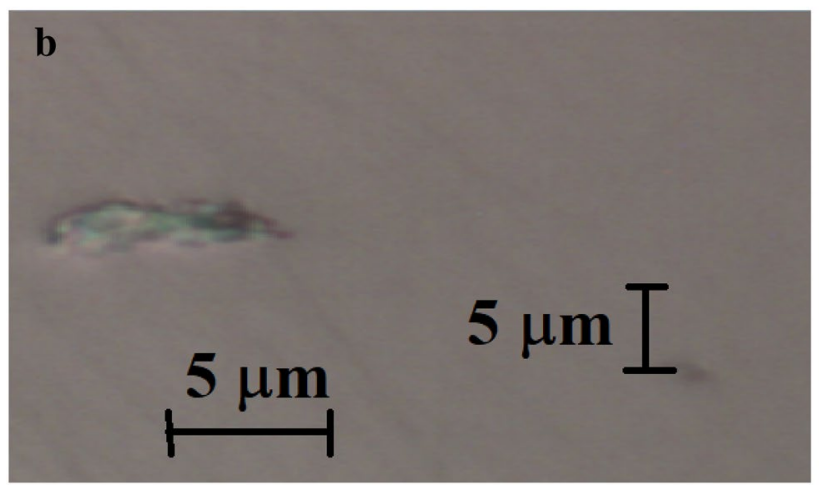

Fig. 7 Optical images of electrodeposited diphenylether from mesityl oxide on platinum (a) and on glassy carbon electrode (b)<smiles>CCOC(=O)NCCOc1ccc(Oc2ccccc2)cc1</smiles>

Fig. 8 Structural formula of fenoxycarb

\section{Fenoxycarb}

The solid material fenoxycarb belongs to carbamates used mainly as insect growth regulator. It differs from diphenylether only with a ligand on one of the phenyl groups (Fig. 8).

In the literature according to our knowledge, no work can be found which shed light on the electrochemistry of fenoxycarb in non-aqueous solvents. In acetonitrile, the lack of deactivation on both electrodes indicates the predominant role of ligand in electrooxidation of fenoxycarb as the peak currents of subsequent voltammograms at around $1.6 \mathrm{~V}$ were identical (Fig. 5). These results suggest that this material oxidizes on its - $\mathrm{NH}$ - group in the carbamate moiety producing a dimer. By increasing the switching potential to more positive values, further reaction of benzene moieties (similarly to diphenylether) can occur leading to the formation 


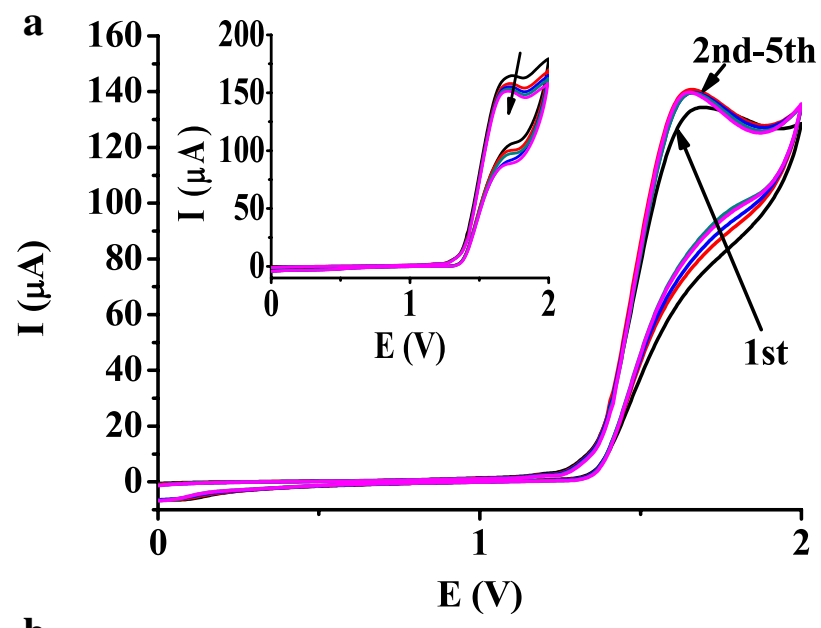

b

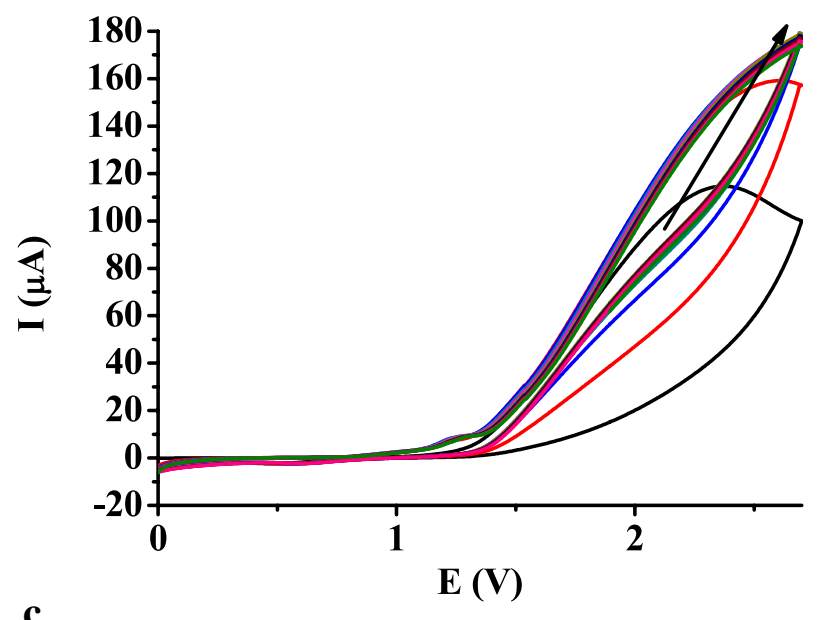

c

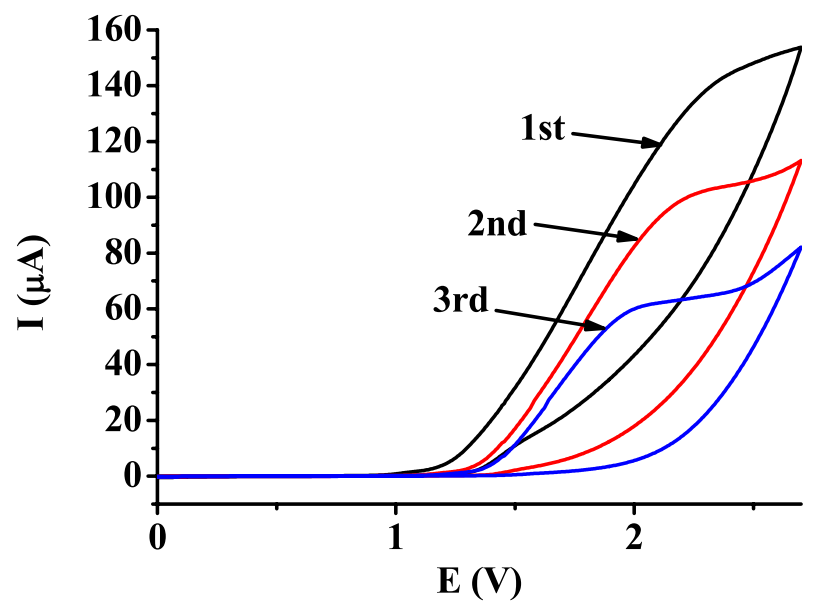

Fig. 9 Voltammograms for fenoxycarb electrooxidation in acetonitrile (a) and in mesityl oxide (b) on platinum electrode $(c=20 \mathrm{mM}$, $v=0.1 \mathrm{~V} / \mathrm{s}$, supporting electrolyte $0.05 \mathrm{M}$ TBAP). Inset graph in part (a) displays results with glassy carbon electrode and part (c) showes curves in mesityl oxide with glassy carbon electrode
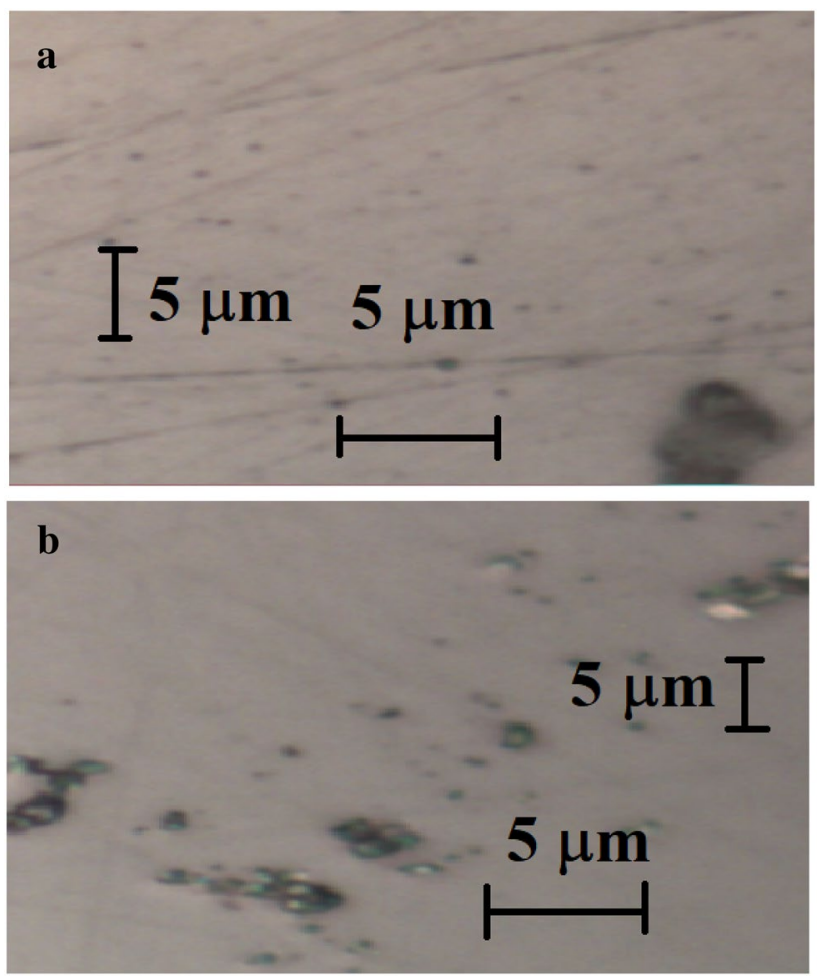

Fig. 10 Optical images of electrodeposited phenoxycarb from mesityl oxide on platinum (a) and on glassy carbon electrode (b)

of deposit which could be clearly indicated with the use of platinum microelectrode. The reproducible current plateaus due to the reaction of carbamate nitrogen could be well separated from the reaction of diphenylether moiety.

As the switching potential was $2 \mathrm{~V}$, only a weak deactivation occurred caused by the solvent on glassy carbon electrode so its behaviour was identical to platinum. The dimerization reaction taking place at both electrodes is shown in the scheme (Scheme 4):

On platinum electrode in acetonitrile, the scan rate dependence of peak currents was studied and as the function of square root of scan rate a linear function could be obtained showing diffusion controlled nature of electrode reaction of fenoxycarb (Fig. 9).

Similar results to that of diphenylether were obtained with both electrodes in mesityl oxide. The potential window was only extended to $2.5 \mathrm{~V}$ as previously polymer formation in acetonitrile above $2 \mathrm{~V}$ occurred. In case of platinum, the peak current increase was more significant due to the side chain so monomer adsorption and diffusion became more clearly seen as a consequence of elevated porosity. The related images verify the development of islands originating from the scarcely soluble products (Fig. 10). 


\section{Conclusion}

The voltammetric studies of phenylether compounds highlighted that the presence of organic substituents and their length highly influences the electrode process and the structure of the electrodeposited films, and moreover, the presence of side chains can inhibit the polymerization process. Electrochemistry of the selected substrates was irreversible, and only oxidation of some of them led to the formation of low conductivity organic layer. These results might be utilized by some practical application in the future, for example, by development of electroanalytical methods for fenoxycarb whose voltammograms showed high reproducibility. On the other hand, the information about monomers characterized in this work can help the development of functional polymers.

Acknowledgements Financial support of the GINOP 2.3.2-15-201600022 grants is highly appreciated.

Funding Open access funding provided by University of Pécs.

Open Access This article is licensed under a Creative Commons Attribution 4.0 International License, which permits use, sharing, adaptation, distribution and reproduction in any medium or format, as long as you give appropriate credit to the original author(s) and the source, provide a link to the Creative Commons licence, and indicate if changes were made. The images or other third party material in this article are included in the article's Creative Commons licence, unless indicated otherwise in a credit line to the material. If material is not included in the article's Creative Commons licence and your intended use is not permitted by statutory regulation or exceeds the permitted use, you will need to obtain permission directly from the copyright holder. To view a copy of this licence, visit http://creativecommons.org/licenses/by/4.0/.

\section{References}

1. S. Ayachi, S. Bergaoui, I.B. Khalifa, A.H. Said, M. Chemek, F. Massuyeau, J. Wery, E. Faulques, K. Alimi, Synt. Met. 166, 22 (2013)

2. A. Gitkis, J.Y. Becker, Electrochim. Acta 55, 5854 (2010)
3. A. Attour, S. Rode, T. Bystron, M. Matlosz, F. Lapicque, J. Appl. Electrochem. 37, 861 (2007)

4. M.R. Ciumag, T. Tzedakis, C.A. Barres, Electrochim. Acta 70, $142(2012)$

5. M. Mellah, J. Zeitouny, S. Gmouh, M. Vaultier, V. Jouikov, Electrochem. Commun. 7, 869 (2005)

6. S. Besbes-Hentati, H. Said, Electrochim. Acta 55, 5636 (2010)

7. J. Marquez, O.P. de Marquez, Rev. Roum. Chim. 38, 775 (1993)

8. A. Attour, S. Rode, A. Ziogas, M. Matlosz, F. Lapicque, J. Appl. Electrochem. 38, 339 (2008)

9. S. Besbes-Hentati, H. Said, M. Bouvet, Electrochim. Acta 52, 4715 (2007)

10. G. Turkoglu, H. Berber, I. Kani, New J. Chem. 39, 2728 (2015)

11. A.A.H. da Rocha, M. Casagrande, L.D. Schaumloffel, Y.P. da Silva, C.M.S. Piatnicki, Energ. Fuel 31, 7076 (2017)

12. L.D. Schaumloffel, J.W.V. Dambros, P.R.B. Fernandes, M. Gutterres, C.M.S. Piatnicki, Fuel 236, 803 (2019)

13. C. Ceballos, H. Fernandez, J. Am. Oil Chem. Soc. 77, 731 (2000)

14. M. Jakubczyk, S. Michalkiewicz, J. Electrochem. Soc. 166, H291 (2019)

15. M. Jakubczyk, S. Michalkiewicz, Int. J. Electrochem. Sci. 14, 6179 (2019)

16. L. Kiss, F. Kovács, H. Li, A. Kiss, S. Kunsági-Máté, Chem. Phys. Lett. 754, 137642 (2020). https://doi.org/10.1016/j.cplet t.2020.137642

17. L. Kiss, D. Bősz, F. Kovács, H. Li, S. Kunsági-Máté, Polym. Bull. 76, 5849 (2019)

18. D.R. Lide, CRC Handbook of Chemistry and Physics, 76th edn. (CRC Press, Boca Raton, 1995), p. 174

19. J.S. Jaworski, M. Cembor, M. Orlik, J. Electroanal. Chem. 582, 165 (2005)

20. N. Papageorgiou, F. Emmenegger, Electrochim. Acta 38, 245 (1993)

21. L.A. Tinker, A.J. Bard, J. Electroanal. Chem. 133, 275 (1982)

22. V. le Berre, L. Angely, J. Simonet, J. Electroanal. Chem. 218, 173 (1987)

23. Y. Martínez, R. Hernández, M. Kalaji, J. Márquez, O.P. Márquez, Synth. Met. 93, 9 (1998)

24. A. Zaouak, F. Matoussi, M. Dachraoui, Int. J. Electrochem. (2011). https://doi.org/10.4061/2011/904570

25. E.G. Cookeas, C.E. Efstathiou, Analyst 117, 1329 (1992)

26. A. Symeonidou, A. Economou, C.E. Efstathiou, M. Dousikou, Anal. Lett. 45, 436 (2012)

27. J. Xu, L. Wan, Y. Li, H. Liu, S. Pu, L. Shen, J. Polym. Sci. A 1(45), 5932 (2007) 